\title{
Long PHILOS plate fixation in a series of humeral fractures
}

\author{
Buchi Arumilli $\cdot$ Norbert Suhm $\cdot$ Jakob Marcel $\cdot$ \\ Daniel Rikli
}

Received: 27 August 2013/Accepted: 24 September 2013/Published online: 2 October 2013

(C) Springer-Verlag France 2013

\begin{abstract}
Aim The purpose of the article is to highlight a specific fracture pattern encountered by us in the osteoporotic upper humerus. We present our results of management of such metadiaphyseal fractures of the upper humerus with less invasive plating. The additional steps taken to improve final outcome and the reasoning behind each are discussed. Patients and methods In our department, a total of 13 fractures (in 12 patients) were managed for a metadiaphyseal fracture of the upper humerus between 2010 and 2013. There were 2 males and 10 females. The average age in the cohort was 74.3 (52-95) years. In 9 fractures, the fracture line was extending above the surgical neck. All patients were managed with a locking compression plate (long PHILOS or LCP) using two approach windows (proximal deltopectoral and a distal anterior or lateral). Patients were evaluated for clinical outcome using the Quick DASH score and assessed for radiological union, complications or re-operations retrospectively.

Results The mean follow-up was 14.3 months (4-36). All fractures were united, and there was no evidence of avascular necrosis or non-union. Two patients showed varus collapse of the anatomical head of which one patient needed change of screws at 12 weeks from index surgery. In patients, when a distal lateral window was used, 2 patients out of 4 had radial nerve palsy post-operatively. In the rest, when the plate was
\end{abstract}

B. Arumilli · N. Suhm · J. Marcel · D. Rikli

Department of Traumatology, University Hospital of Basel, Spitalstrasse 21, 4031 Basel, Switzerland

B. Arumilli ( $₫)$

Department of Trauma \& Orthopaedics, Central Manchester University Hospitals NHS Foundation Trust, Oxford Road, Manchester M13 9WL, UK

e-mail: rajjuorth@gmail.com twisted by $45^{\circ}$ to allow anterior placement using the brachialis split, none had radial nerve injury.

Conclusion The osteoporotic bone failing under a lowenergy mechanism seemed to dictate this fracture pattern. The fracture is either a bending wedge or a long spiral with or without a large butterfly and often extends into the humeral head. The fractures are better managed surgically, a primary reduction allowing contact of fragments is essential, and using an anterior window distally with a $45^{\circ}$ contoured plate will achieve good plate placement as well as decreases the risk of radial nerve injury considerably compared to total lateral plate positioning.

Keywords Fracture $\cdot$ Humerus - Locking compression plate $\cdot$ Radial nerve palsy .

Metadiaphysis · Osteoporosis

\section{Introduction}

Fractures of the humerus are frequently managed nonoperatively with satisfactory results [1]. A minority of them will need surgical stabilisation for classic indications. The option of nailing or plating humerus fractures is debated with each method having advantages of its own [2]. The upper humerus is a common site for osteoporotic fractures, and low-energy falls can result in complex fracture patterns in this region [3], which often extend into the humeral head. These fractures are too high for humeral bracing and the prolonged non-operative management may have considerable morbidity. Therefore, the fractures involving the metadiaphyseal area of the proximal humerus may be preferably treated surgically. Locking compression plate is an accepted method to treat such fractures to address problems of proximal fixation and better purchase in osteoporotic bone $[4,5]$. 
Minimally and less invasive plating has been performed in the humerus using such plates with good results $[6,7]$. The concept of a contoured long plate to be applied over the lateral part of the proximal humerus and anteriorly over the distal part is not new [8-10].

\section{Patients and methods}

Twelve patients with 13 metadiaphyseal fractures (1 bilateral) of the upper humerus managed in our unit between June 2010 and January 2013 were retrospectively reviewed. There were 2 males and 10 females in the cohort. The average age was 74.3 (52-95) years. The side involved was 5 right and 6 left, and one patient had bilateral fractures. None of the patients had a nerve palsy on presentation. The Association for Osteosynthesis/Association for the Study of Internal Fixation (AO/ASIF) classification was used, and the subtypes are detailed in Table 1 along with the cohort details, technique used and final outcome. In 9 fractures, the fracture line was extending into the proximal humerus.

\section{Surgical technique}

After appropriate anaesthesia, patients were positioned in a deck chair position. The image intensifier position was checked for adequate anteroposterior, lateral and axillary views. Proximally, a deltopectoral window was used. After exposure of the fracture proximally, reduction was performed by closed means initially. After checking the initial reduction with the image intensifier, any fracture fragments that could be lagged were fixed with screws. If there was no such possibility, a non-absorbable Ticron suture was used as a cerclage to aid contact of fragments. Distally, an anterior (8 patients) or a lateral window (4 patients with 5 fractures) was used for plating. In a distal lateral approach, the radial nerve was identified between the brachialis and brachioradialis before plating. In an anterior approach distally, the brachialis was split between lateral $1 / 3$ and medial $2 / 3$. In the latter, the plate used was twisted by around $45^{\circ}$ to aid anterior placement. After using a locking drill sleeve for control, the plate was slid in the sub muscular extraperiosteal plane. The plate was passed into the subdeltoid space and then through the subbrachial space and retrieved either laterally or anteriorly. After proper positioning of the plate, one conventional screw was inserted to approximate the plate to the shaft and subsequently fixed with locking screws (minimum of 6 cortices distally). Final reduction was checked and wound edges were approximated with prolene without drains. Post-operative physiotherapy was started on day one, and patients were discharged home when safe, but continued physiotherapy on an outpatient basis.

Table 1 The demography, fracture, management, complications and outcome details of the cohort

\begin{tabular}{|c|c|c|c|c|c|c|c|c|c|}
\hline $\begin{array}{l}\text { Serial } \\
\text { number }\end{array}$ & Gender & Age & $\begin{array}{l}\mathrm{AO} / \mathrm{ASIF} \\
\text { subtype }\end{array}$ & $\begin{array}{l}\text { Approach } \\
\text { (proximal-distal) }\end{array}$ & Implant used & $\begin{array}{l}\text { Radial } \\
\text { nerve palsy }\end{array}$ & Other complications & $\begin{array}{l}\text { Proximal } \\
\text { extension }\end{array}$ & $\begin{array}{l}\text { Quick } \\
\text { DASH }\end{array}$ \\
\hline 1 & $\mathrm{~F}$ & 67 & A1 & Lateral-lateral & 10-hole PHILOS & No & None & Yes & 0 \\
\hline 2 & $\mathrm{~F}$ & 73 & A1 & Lateral -anterior & $\begin{array}{l}\text { 10-hole PHILOS } \\
\text { contoured }\end{array}$ & No & $\begin{array}{l}\text { Minimal varus } \\
\text { collapse }\end{array}$ & Yes & 36.4 \\
\hline 3 & M & 73 & B3 & Lateral-lateral & 10-hole PHILOS & Yes & None & Yes & 0 \\
\hline 4 & $\mathrm{~F}$ & 93 & A1 & Lateral-anterior & $\begin{array}{l}\text { 10-hole PHILOS } \\
\text { contoured }\end{array}$ & No & None & Yes & 2.3 \\
\hline 5 & $\mathrm{~F}$ & 95 & B1 & Lateral-anterior & $\begin{array}{l}\text { 10-hole PHILOS } \\
\text { contoured }\end{array}$ & No & None & No & 0 \\
\hline 6 & $\mathrm{~F}$ & 79 & $\mathrm{C} 1$ & Lateral-anterior & $\begin{array}{l}\text { 10-hole PHILOS } \\
\text { contoured }\end{array}$ & No & None & Yes & 2.3 \\
\hline 7 & $\mathrm{~F}$ & 88 & A1 & Lateral-lateral & 8-hole PHILOS & No & None & No & 70.5 \\
\hline $8^{\mathrm{a}}$ & ${ }_{\text {Right }}$ & 53 & B3 & Lateral-lateral & 10-hole PHILOS & No & $\begin{array}{l}\text { Screw penetration } \\
\text { needing exchange }\end{array}$ & Yes & 72.7 \\
\hline $9^{\mathrm{a}}$ & F Left & 53 & B3 & Lateral-lateral & 10-hole PHILOS & Yes & None & Yes & 63.6 \\
\hline 10 & $\mathrm{~F}$ & 52 & $\mathrm{C} 1$ & Lateral-anterior & $\begin{array}{l}\text { 10-hole PHILOS } \\
\text { contoured }\end{array}$ & No & None & Yes & 0 \\
\hline 11 & M & 61 & A1 & Lateral-anterior & $\begin{array}{l}\text { 10-hole PHILOS } \\
\text { contoured }\end{array}$ & No & None & No & 31.8 \\
\hline 12 & $\mathrm{~F}$ & 92 & A1 & Lateral-anterior & $\begin{array}{r}\text { 9-hole LCP } \\
\text { contoured }\end{array}$ & No & None & No & 68.2 \\
\hline 13 & $\mathrm{~F}$ & 66 & $\mathrm{C} 1$ & Lateral-anterior & $\begin{array}{l}\text { 10-hole PHILOS } \\
\text { contoured }\end{array}$ & No & None & Yes & 18.2 \\
\hline
\end{tabular}

${ }^{a}$ Serial number 8 and 9 denote the details of each side of the same patient with bilateral fractures 

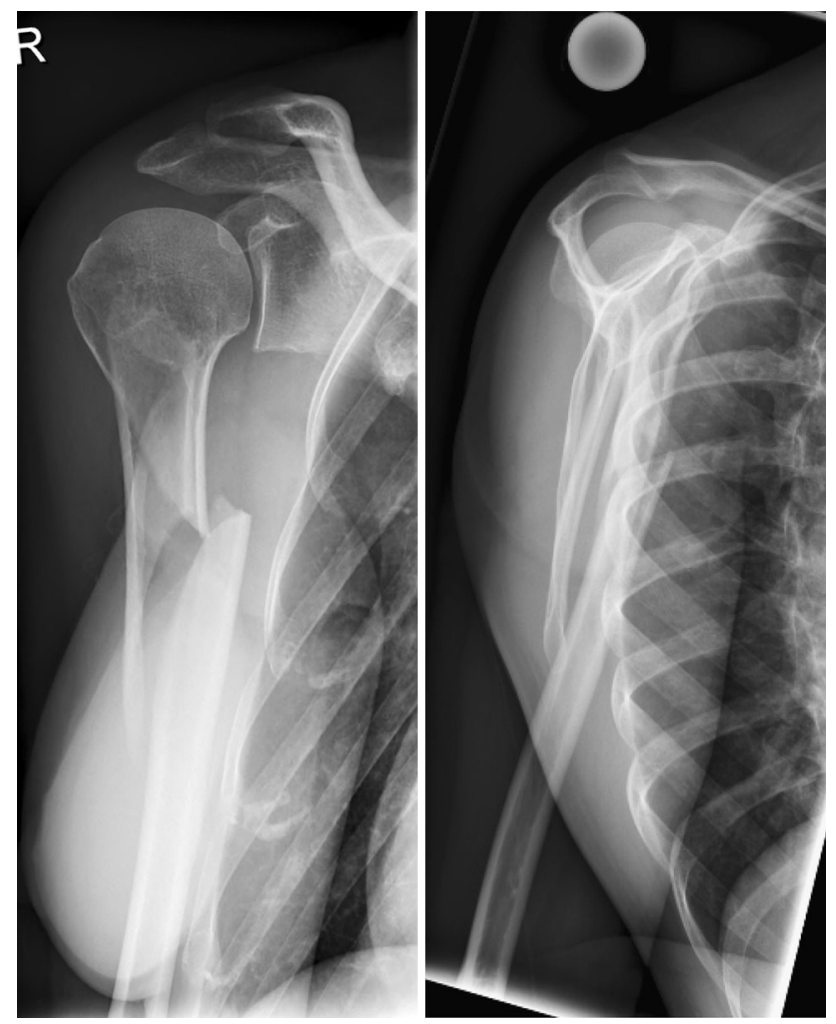

Figs. 1 and 2 Pre-operative anteroposterior and lateral radiographs showing a long spiral metadiaphyseal fracture of the right humerus with a large lateral butterfly fragment

\section{Follow-up}

All patients were followed up as outpatients with X-rays at 6 weeks, 3 months and thereafter at regular intervals depending on the progress of fracture healing. Bony union on X-ray was defined as bony bridging of at least three cortices on the anteroposterior and lateral views. The final outcome was assessed using the Quick DASH (Disabilities of Arm, Shoulder and Hand) tool.

\section{Results}

After a mean follow-up of 14.3 (4-36) months, all patients showed fracture union and there were no non-unions or avascular necrosis of humeral head. In two fractures (out of five) managed with a proximal deltopectoral and a distal lateral approach, there was radial nerve palsy post-operatively. The two patients with radial nerve palsy improved significantly (grade 4 power) at 3 months and completely by 6 months. The Quick DASH tool showed an average score of $28.1(0-72.5)$ with 4 patients complaining of inability to perform heavy household work or sports, but none had any arm pain. The Figs. 1 and 2 show the preoperative radiographs of a long spiral metadiaphyseal
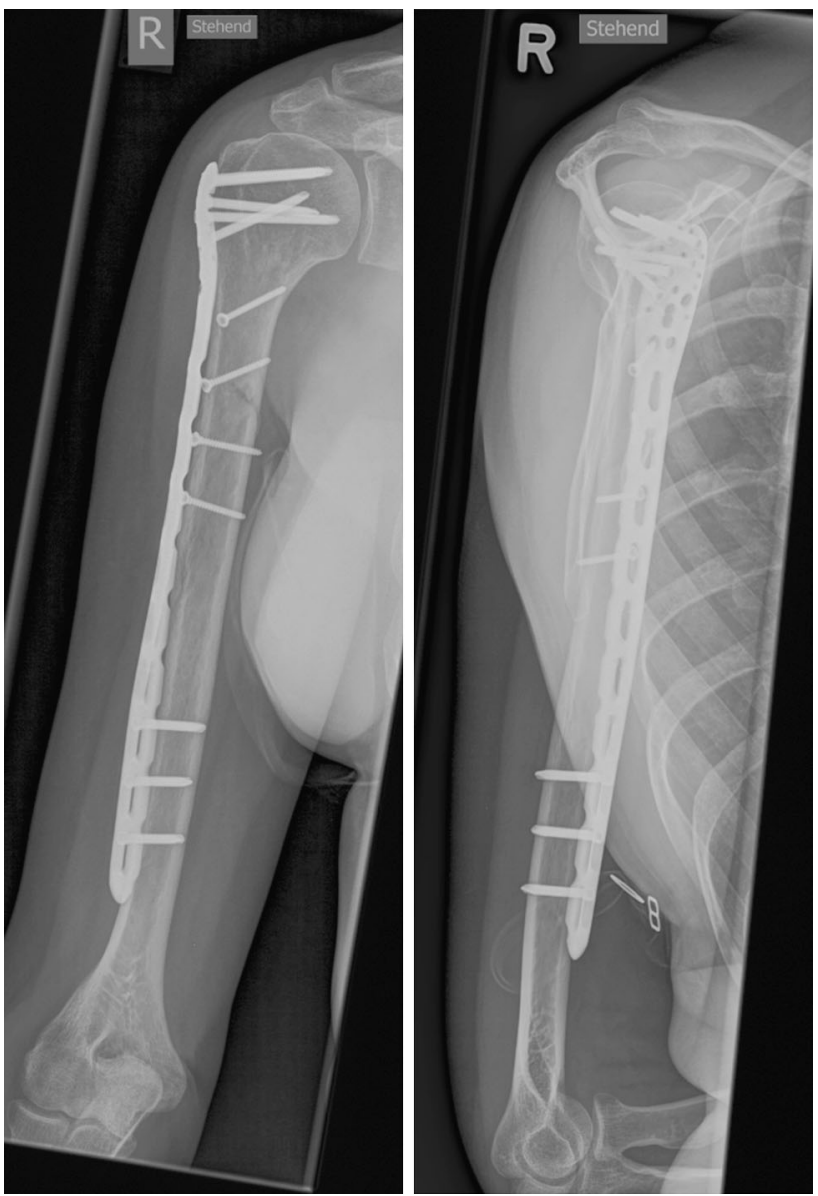

Figs. 3 and 4 Post-operative anteroposterior and lateral radiographs of the right humerus at 3-month follow-up showing union

fracture of the right upper humerus with a large butterfly fragment. Figures 3 and 4 show the follow-up radiographs of the same patient after 3 months.

\section{Discussion}

The fractures of the proximal humeral metadiaphysis are a challenge to manage for various reasons. They occur in elderly patients, in osteoporotic bone, often extend into the head, thus are difficult to manage with simple LCP and will need an extensile approach for formal internal fixation. The common patterns of fracture seen in our cohort were a bending wedge or a long spiral type with or without a large butterfly fragment. The problem of maintaining stability to facilitate fracture healing would not allow for early rehabilitation in such fractures with non-operative management. Internal fixation with a Locking Proximal Humeral Plate PHILOS (Synthes, Oberdorf, Switzerland) [11] allows stable proximal fixation as it is contoured to the anatomy of lateral aspect of the proximal humerus (Fig. 5). 


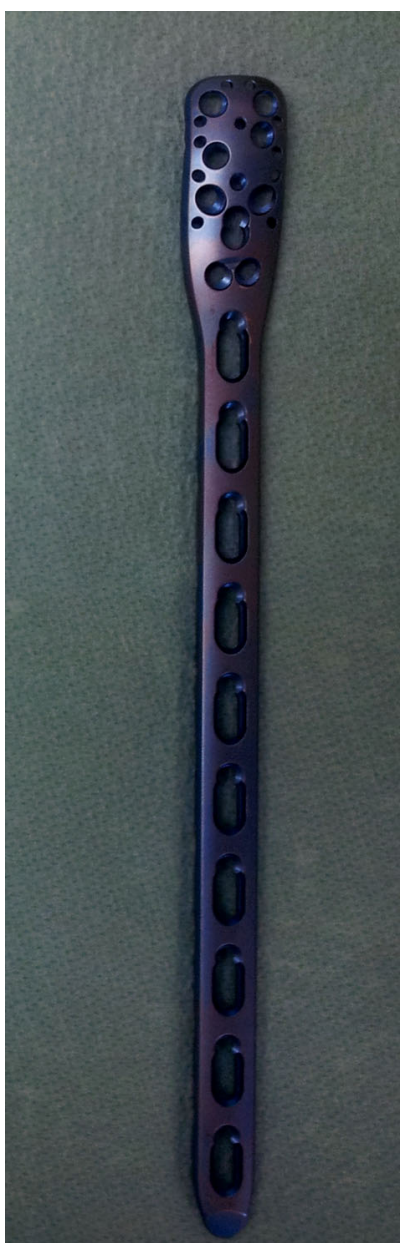

Fig. 5 A long PHILOS plate

This works well in osteoporotic bone as angular stability is provided with screws locking into the plate and their threedimensional distribution in the humeral head [12].

The common mode of application of a long plate in a comminuted fracture is to allow indirect fracture healing by bridging for which the screws should be at a considerable distance from the fracture site. The proximal humeral locking plate is a very stiff implant in all modes of loading and shows minimal deformation [13, 14]. The locking plate in this cohort was used in a neutralisation mode, and in all patients, the fracture fragments were brought into contact with each other. A lag screw was applied or a strong suture passed as a cerclage to achieve contact between fragments. This step is important as fixing the fragments even in minimal distraction with a stiff construct like proximal humeral locking plate will delay union [15].

Osteoporosis poses two difficulties in these fractures, altered mechanics and biology [3]. Although the healing progresses through the normal stages, the process is prolonged. The quality and the quantity of healing are reduced in osteoporotic bone models in animal studies [15]. Hence, the fracture fragments should be approximated either by
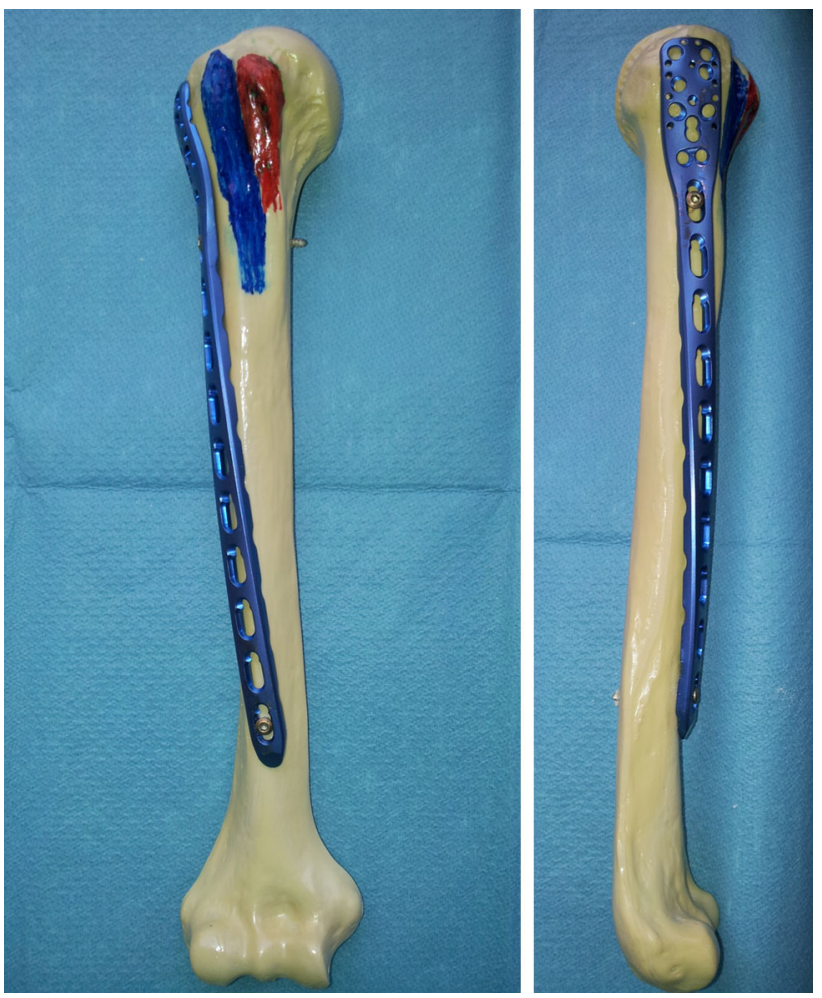

Figs. 6 and 7 Anteroposterior and lateral views of a contoured 10-hole PHILOS plate applied to a humerus model

direct or by indirect methods to minimise the risk of delayed or non-union which results in implant failure. This is reflected in the increased rate of complications following operative treatment for metaphyseal fractures in the elderly $[16,17]$. A hybrid construct with a compression screw initially as a reduction aid is better in osteoporotic bone and does not adversely influence the overall strength of the fixation [18].

Less invasive techniques in plating humerus have been described using different approaches with good results [6, $7,9]$. These are technically demanding and need considerable surgical experience to get a satisfactory reduction [19]. The placement of plate on the lateral aspect of humerus proximally and on the anterior surface distally makes perfect sense. This allows minimal possibility of complications and nerve injury in each zone. This principle was well described as anterior plating can interfere with the long head of biceps, whereas a lateral plate at the lower third of humerus can put the radial nerve at risk [8,9]. A lateral window to allow total lateral placement of the long PHILOS plate was done in 4 patients. Two of the four patients had dense radial nerve palsy post-operatively. The nerve was identified and isolated in each case in spite of which 2 patients ended with radial nerve palsy. We feel that the simple manipulation of the nerve during plating in an area where it is tethered by the lateral intermuscular septum and has decreased mobility can lead to an injury. 


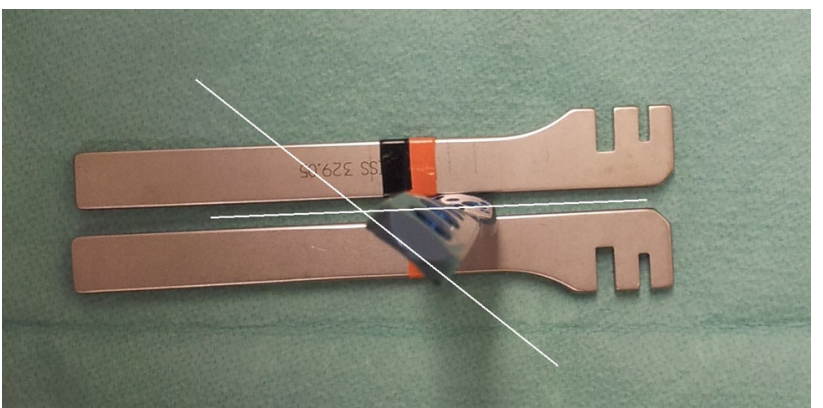

Fig. 8 End on view of a $45^{\circ}$ contoured long PHILOS plate to appreciate the orientation

In patients who had a distal anterior approach, the plate was twisted in the middle by approximately $45^{\circ}$. The Figs. 6 and 7 show the anteroposterior and lateral views of a twisted long 10-hole PHILOS plate applied on a humerus model, and Fig. 8 shows the end on view of the plate to appreciate the degree of contouring. This allowed the flush placement of the plate over the anterior aspect of the distal third humerus using a brachialis split approach, where the radial nerve is protected laterally and the musculocutaneous nerve medially. We did not encounter any difficulties in this step or implant failure due to stress raiser at the point of twist. We have since exclusively used the anterior window distally with a contoured PHILOS plate in such fractures.

Studies have shown that long PHILOS is a satisfactory solution for the metadiaphyseal fractures of the humerus in general [20]. Our article aims to bring to the notice of the readers the entity of a low-energy bending wedge or a long spiral fracture with or without a large butterfly fragment occurring in osteoporotic bone, which will need a long locking plate in a neutralisation mode with adequate reduction in fragments. The additional contouring of the plate with an anterior approach distally will reduce the risk of radial nerve damage considerably.

Acknowledgments We express our sincere thanks to Ms. Bojana Savic our study nurse for her role in collecting the outcome scores for the patients in the study.

Conflict of interest Dr. Arumilli has nothing to disclose. Dr. Suhm reports grants from AO Foundation, personal fees from Roche, personal fees from Eli Lilly, personal fees from DePuy-Synthes and personal fees from MSD, outside the submitted work. Dr. Jakob has nothing to disclose. Dr. Rikli reports personal fees from DePuySynthes, outside the submitted work.

\section{References}

1. Gosler MW, Testroote M, Morrenhof JW et al (2012) Surgical vs non-surgical interventions for treating humeral shaft fractures in adults. Cochrane Database Syst Rev 1:CD08832
2. Kurup H, Hossain M, Andrew JG (2011) Dynamic compression plating versus locked intramedullary nailing for humeral shaft fracture in adults. Cochrane Database Syst Rev 15(6):CD005959

3. Giannoudis PV, Schneider E (2006) Principles of fixation of osteoporotic fractures. J Bone Joint Surg Br 88-B:1272-1278

4. Egol KA, Kubiak EN, Fulkerson E, Kummer FJ, Koval KJ (2004) Biomechanics of locked plates and screws. J Orthop Trauma 18(8):488-493

5. Strauss EJ, Schwarzkopf R, Kummer F, Egol KA (2008) The current status of locked plating: the good, the bad, and the ugly. J Orthop Trauma 22(7):479-486

6. Aksu N, Karaca S, Kara AN, Işiklar ZU (2012) Minimally invasive plate osteosynthesis (MIPO) in diaphyseal humerus and proximal humerus fractures. Acta Orthop Traumatol Turc 46(3):154-160

7. Apivatthakakul T, Phornphutkul C, Laohapoonrungsee A, Sirirungruangsarn Y (2009) Less invasive plate osteosynthesis in humeral shaft fractures. Oper Orthop Traumatol 21(6):602-613

8. Fernández Dell'Oca AA (2002) The principle of helical implants: unusual ideas worth considering. Case studies. Injury 33(Suppl 1):SA29-SA40

9. Yang KH (2005) Helical plate fixation for treatment of comminuted fractures of the proximal and middle one-third of the humerus. Injury 36(1):75-80

10. Gardner MJ, Griffith MH, Lorich DG (2005) Helical plating of the proximal humerus. Injury 36(10):1197-1200

11. Konrad G, Bayer J, Hepp P, Voigt C, Oestern H, Kääb M, Luo C, Plecko M, Wendt K, Köstler W, Südkamp N (2010) Open reduction and internal fixation of proximal humeral fractures with use of the locking proximal humerus plate. Surgical technique. J Bone Joint Surg Am 92(Suppl 1):85-95

12. Hepp P, Josten Christoph (2007) Biology and biomechanics in osteosynthesis of proximal humerus fractures. Eur J Trauma Emerg Surg 33(4):337-344

13. Hessmann MH, Korner J, Hofmann A, Sternstein W, Rommens PM (2008) Angle-fixed plate fixation or double-plate osteosynthesis in fractures of the proximal humerus: a biomechanical study. Biomed Tech 53(3):130-137

14. Röderer G, AbouElsoud M, Gebhard F, Claes L, Aschoff AJ, Kinzl L (2010) Biomechanical investigation of fixed-angle plate osteosynthesis of the proximal humerus. Unfallchirurg 113(2):133-138

15. Clavert P, Adam P, Bevort A, Bonnomet F, Kempf JF (2010) Pitfalls and complications with locking plate for proximal humerus fracture. J Shoulder Elbow Surg 19(4):489-494

16. Namakung Matthail H, Applezard R, Jansen J et al (2001) Osteoporosis influences the early period of fracture healing in a rat osteoporotic model. Bone 28:80-86

17. Kanakaris NK, Giannoudis PV (2010) Locking plate systems and their inherent hitches. Injury 41(12):1213-1219

18. Gardner MJ, Griffith MH, Demetrakopoulos D, Brophy RH, Grose A, Helfet DL, Lorich DG (2006) Hybrid locked plating of osteoporotic fractures of the humerus. J Bone Joint Surg Am 88(9):1962-1967

19. Concha JM, Sandoval A, Streubel PN (2010) Minimally invasive plate osteosynthesis for humeral shaft fractures: are results reproducible? Int Orthop 34(8):1297-1305

20. Zhang H, Ni W, Gao S, Liang X, Zhou A (2009) Long PHILOS locking compression plate for treatment of proximal humerus and humeral shaft fractures. Zhongguo Xiu Fu Chong Jian Wai Ke Za Zhi 23(4):419-422 